\title{
Smart Inverters for Microgrid Applications: A Review
}

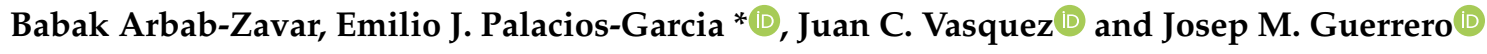 \\ Department of Energy Technology, Aalborg University, Pontoppidanstraede 111, DK-9220 Aalborg, Denmark; \\ baz@et.aau.dk (B.A.-Z.); juq@et.aau.dk (J.C.V.); joz@et.aau.dk (J.M.G.) \\ * Correspondence: epg@et.aau.dk; Tel.: +5-5028-0730
}

Received: 6 February 2019; Accepted: 24 February 2019; Published: 4 March 2019

check for

updates

\begin{abstract}
In a microgrid, with several distributed generators (DGs), energy storage units and loads, one of the most important considerations is the control of power converters. These converters implement interfaces between the DGs and the microgrid bus. In order to achieve higher functionality, efficiency and reliability, in addition to improving the control algorithms it is beneficial to equip the inverters with "smart" features. One interpretation of "smartness" refers to minimizing the requirement of communication and therefore switching from centralized to decentralized control. At the same time, being equipped with efficient and state of the art communication protocols also indicates "smartness" since the requirement of communication cannot be completely omitted. A "smart inverter" should offer some features such as plug and play, self-awareness, adaptability, autonomy and cooperativeness. These features are introduced and comprehensively explained in this article. One contribution discussed here is the possibility of achieving long-range wireless communication between inverters to empower various control schemes. Although current efforts aim to modify and improve power converters in a way that they can operate communication free, if a suitable and functional communication protocol is available, it will improve the accuracy, speed and robustness of them.
\end{abstract}

Keywords: smart inverter; microgrid; distributed generation; communication; wireless

\section{Introduction}

Microgrids are a form of small-scale grids that contain DGs, energy storage units and linear or nonlinear loads that can operate in grid-connected or islanded mode. In microgrids, DGs can be of renewable or non-renewable nature, and the components of such grids are interfaced by power converters [1-3]. The CIGRE working group C6.22 Microgrid Evolution Roadmap (WG6.22) provides a standard definition for microgrids: Microgrids are electricity distribution systems containing loads and distributed energy resources, (such as distributed generators, storage devices, or controllable loads) that can be operated in a controlled, coordinated way either while connected to the main power network or while islanded [4]. In the early years of introducing renewable energy sources (RES), the power generated by them was not substantial in comparison to the large conventional generators powering up the grid, therefore, their impact on the performance of the grid was almost unnoticeable. At those years, the scheme was to allow them to produce as much power as possible and inject it into the grid by using their own algorithms. The main conventional generators could regulate the small unbalances and fluctuations caused by these DGs [5,6].

However, due to the recent development and expansion of renewable energy technologies, RESs have become a major energy source in some countries. Therefore, the quality and parameters of their injected power into the grid must be carefully monitored. In other words, their operation needs to be accompanied by power management schemes centered on power sharing or load sharing to be fully controllable [7]. 
The concept of power sharing between parallel DGs was initially introduced for synchronous generators in large-scale grids, and recently some novel approaches were proposed to incorporate the idea of droop control algorithms into microgrids [8-13]. Although using droop-based methods can be very beneficial, some drawbacks can be identified. For example, the trade-off between voltage regulation and load sharing [14], the ineffective management of harmonics introduced by nonlinear loads [15] and the slow dynamic response due to the incorporation of low pass filters for calculating average values of active $(P)$ and reactive $(Q)$ power [16]. Because of the problems of conventional droop control, its principles have undergone numerous modifications and improvements. In [17] a new droop scheme aiming to regulate the voltages of each inverter and improve current sharing was proposed. When nonlinear loads such as rectifiers are present, they introduce harmonics in the system, and prevent droop control from working efficiently. In [18], this problem was addressed and regulated by adding harmonic droop characteristics. This issue can also be compensated by using a virtual variable impedance in series with the load. As its name indicates, this impedance is purely simulated and no physical components are added to the circuit [19-22]. In [13] a hierarchical control method was proposed to control microgrids. This hierarchy consists of three layers: the primary level is droop control; the secondary level compensates for the unbalances and deviations resulted by the first level by sending voltage and frequency references; and the tertiary level (energy management level) which sends the droop coefficients is where the connection with the grid. In this method, only the first level works as communication free, since it is droop control, while the rest of them require communication between inverters.

Although most of the existing microgrids are supplied in AC to simplify their interface with utility grids, DC microgrids are attracting more attention in recent years. This is not only because of the DC nature of several RESs such as solar energy, fuel cells and energy storage units like batteries and supercapacitors, but also because of some additional benefits. In a DC microgrid, the problem of harmonic current sharing no longer exists. Neither is there reactive power sharing. What is more, the system can be more efficient and simple as there is no more need for AC-DC-AC converters. These converters are commonly used for wind or hydro energy conversion and they consist of two back-to-back bidirectional AC-DC converters with a DC link. This DC link decouples two 3-phase AC systems with different parameters enabling the maximization of the output power by using maximum power point tracking (MPPT) algorithms and the synchronization with the grid [12,13,23-26]. The hierarchical control for DC microgrids is similar to the one proposed for AC but simpler. At the primary level, the droop control of DC microgrids only consists of voltage versus current droop in contrast to AC microgrids where active and reactive power droop controls must be provided. The secondary control regulates voltage deviations resulted from the primary control and restores the values to nominal levels, which is only applied at islanded mode. In grid-connected mode, the references comes from the grid parameters. Similar to AC microgrids the tertiary control regulates the power flow with a stiff DC grid at energy management level $[13,27,28]$.

The power converters are able to play different roles when incorporated into a microgrid, namely grid forming, grid feeding and grid following. These are defined in [10] alongside with control structures at the converter level. Another fact that should be considered is that DGs in a microgrid are commonly placed far away from each other. Even though using various droop control schemes reduces the requirement of communication between inverters, a link is unavoidable if a good power sharing control scheme is desired. However, to implement fast communication links which can fulfill the requirements of this kind of applications and be sufficiently reliable can be very costly [10,29]. Therefore, finding a long range and preferably low operating cost communication protocol to fill in for the current lack of effective bidirectional communication between inverters can be considered a very promising field for research and development. In this paper, a literature review on "smart inverters" and their application to microgrids is conducted. The "smartness" features are introduced and explained in detail. In each section, different methods and challenges regarding each of these indicators are addressed and are empowered by equations and tabular or illustrative information 
where required. The technological achievements, as well as present gaps, are introduced throughout the article. Finally, the discussion section presents the main conclusions drawn from the study and provides insights into possible paths for further research and development.

\section{Smart Inverters}

Defining a device as "smart" means that it has the ability to operate efficiently and autonomously with limited operator intervention required. The role of an inverter in a microgrid is to operate as an interface between energy generation and consumption points. Therefore, its role is not limited to AC DC conversion or vice versa (depending on the type of the converter) but also to control the power flow, sense faults, disconnect when necessary and other functions. Since these are the main factors that concern the microgrid control, it can be stated that the inverters are the thinking and processing components of a microgrid, which collect data and configure themselves in order to operate in a safe, controlled and effective environment. Furthermore, each power converter acting as an interface for a distributed energy resource (DER) to the grid has to fulfill the requirements of the IEEE 1547 standards series [30]. These standards have been implemented and periodically revised to deal with aspects such as voltage and power quality, grounding, islanding detection, etc $[5,8,13]$. The latest version, IEEE 1457-2018, was modified for inverter based microgrids. What is more, in the last 2018 release of the standard the DERs require to contain grid-supporting features such as voltage and frequency ride through capabilities and continue to function in case of parameter unbalances. This is in contrast to the original version, IEEE 1457-2003, that trip the DER offline in these situations [30-33].

In [34], the major indicators of smartness for an inverter were described. Each of these indicators contains some operational features that are described in separate sections and sub-sections in this article. Figure 1 is an illustration of the "smartness" indicators and their operational features.

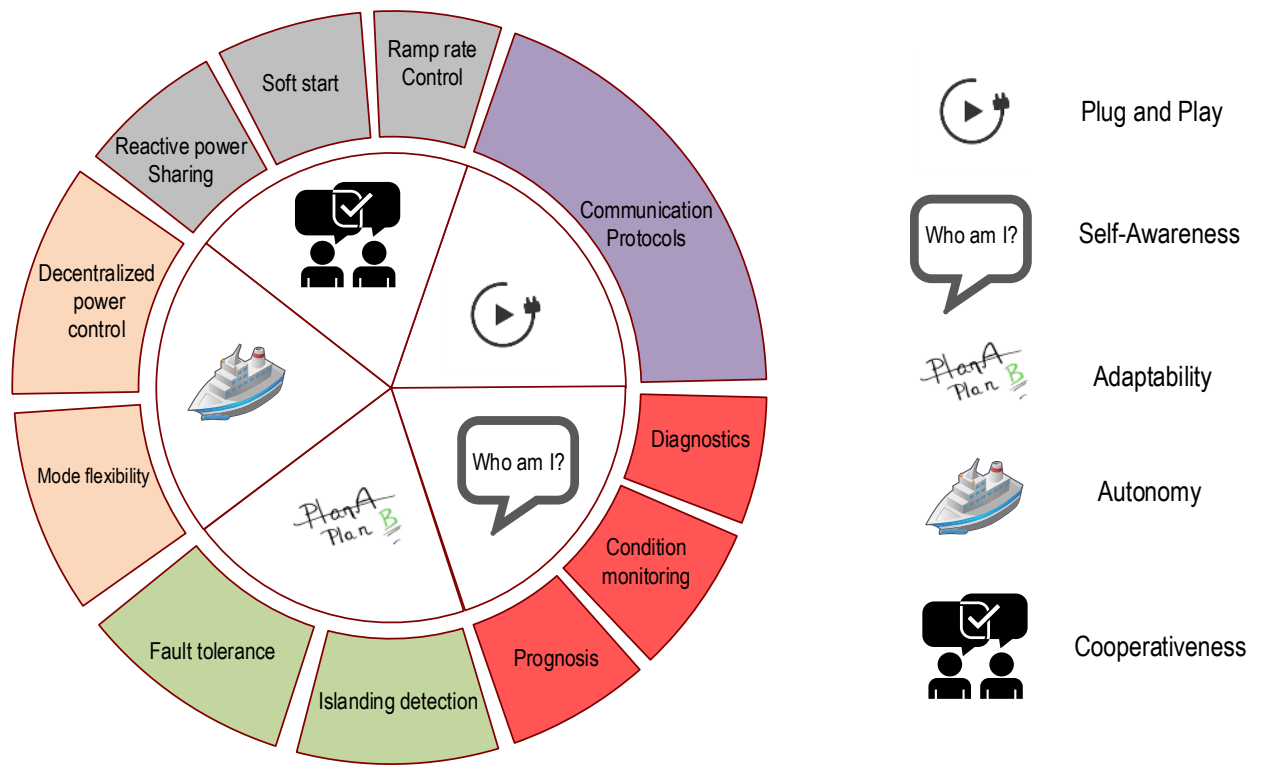

Figure 1. Indicators of smartness for smart inverters.

\subsection{Plug and Play}

For an inverter to be able to present this feature, it needs to be compatible with the standard communication protocols that control the microgrid. As mentioned before, the modern hierarchical control of microgrids still requires communication between different components of the grid even if they are droop based. This means that a reliable long-range communication protocol is required. In [35], the different communication technologies for smart grids has been introduced accompanied by a discussion on their advantages and disadvantages. The benefits and drawbacks of wireless 
connection for smart grids are presented comprehensively in [36]. Generally, the major communication requirements for a smart grid or microgrid have been presented $[35,37,38]$ as follows:

- Data rate: This is one of the most important requirements, as not all of the communication structures are able to provide the required data rate. For example for a home or industrial area network application (HAN and IAN) the required data rate is less than $100 \mathrm{kbps}$. In contrast to a wide area application (WAN) where this figure can rise to more than 10 Mbps [39].

- Range: A microgrid consists of several DGs, energy storage systems (ESSs) and consumers. These are all interfaced to the microgrid bus by inverters that need to be able to communicate. Depending on the size of the microgrid the distance between these points can be noticeable (in the scale of tens of kilometers or more) so no all communication technologies are able to fulfill this requirement.

- Security: If the communication structure is not secure enough [40], the whole system will be vulnerable to both physical and cyber-attacks. This is a challenging aspect regarding some natural characteristics of a smart grid. For example, the smart grid is very sensitive to latency and implementing conventional security measures might introduce new and more delays [41].

- Latency: Depending on the function of the device in a smart grid, the allowed threshold for the latency is different. In the concept of inverter control signals, this allowance is less than ten milliseconds.

- Reliability and Scalability.

In order to nominate a communication protocol for smart grids and subsequently smart inverters, the aspects addressed above should be considered carefully and the differences between machine-to-machine (M2M) communication and human-to-human ( $\mathrm{H} 2 \mathrm{H})$ communication should be understood. Both wired and wireless communication technologies can be implemented for smart inverters.

\subsubsection{Wired Communication Technologies}

There are some benefits to using wired communication technologies. They are more immune to interferences and their operational dependency on batteries are less than with wireless technologies. However, they present some drawbacks such as high implementation costs and signal quality degradation in power line communication (PLC) technology [35]. In fact this technology is the only wired technology with an implementation cost comparable to wireless methods, as it uses power cables for transferring data [37,42]. In addition, this technology has wide coverage, easy to implement and long range [43].

PLC technology has been divided into two categories. Narrow band (NB) PLCs, which operate in transmission frequencies bellow $500 \mathrm{kHz}$ and broadband (BB) PLCs which use higher frequencies of up to $30 \mathrm{MHz}$. NB-PLC technology provides lower data rate but a much higher range. In contrast, BB-PLCs characteristics are exactly the opposite with also lower reliability. Regarding these facts, for smart inverters or smart grids the NB-PLC is a more suitable option, whereas BB-PLC can be considered for home applications [37,44,45]. In addition to PLC technologies, there are several other supports and protocols available in this category such as optical fiber based communication, Digital Subscriber Lines (DSL), coaxial cable and Ethernet [37,38]. A brief comparison of characteristics of wired communication technologies is summarized in Table 1. 
Table 1. Comparison of different wired technologies for M2M communication.

\begin{tabular}{|c|c|c|c|c|c|}
\hline \multicolumn{2}{|c|}{ Technology } & Data Rate & \multirow{2}{*}{$\begin{array}{c}\text { Coverage } \\
150 \mathrm{~km}\end{array}$} & \multirow{3}{*}{$\begin{array}{l}\text { Disadvantages } \\
\text { Difficult to achieve high bit rates. } \\
\text { Signal attenuation. } \\
\text { Interference from electric component } \\
\text { connected to the line. }\end{array}$} & \multirow{3}{*}{$\begin{array}{c}\text { References } \\
\\
{[37,38,46-48]}\end{array}$} \\
\hline & NB & $10-500 \mathrm{kbps}$ & & & \\
\hline PLC & $\mathrm{BB}$ & 10-200 Mbps & $1.5 \mathrm{~km}$ & & \\
\hline $\begin{array}{l}\text { Fiber } \\
\text { optics }\end{array}$ & $\begin{array}{l}\text { PON } \\
\text { AON }\end{array}$ & $\begin{array}{c}100 \text { Mbps-2.5 Gbps } \\
100 \mathrm{Mbps}\end{array}$ & $\begin{array}{l}10-60 \mathrm{~km} \\
10 \mathrm{~km}\end{array}$ & $\begin{array}{c}\text { High capital costs. } \\
\text { Difficult to upgrade. }\end{array}$ & {$[37,38,46-48]$} \\
\hline DSL & $\begin{array}{l}\text { HDSL } \\
\text { ADSL } \\
\text { VDSL }\end{array}$ & $\begin{array}{c}2 \mathrm{Mbps} \\
\text { 1.3-8 Mbps } \\
\text { 16-85 Mbps }\end{array}$ & $\begin{array}{c}3.6 \mathrm{~km} \\
5 \mathrm{~km} \\
1200 \mathrm{~m}\end{array}$ & $\begin{array}{c}\text { Possible data quality degradation. } \\
\text { High operational costs. }\end{array}$ & \\
\hline
\end{tabular}

\subsubsection{Wireless Communication Technologies}

In wireless technologies, one initial and obvious choice can be using the existing cellular network, as it is already available and globally dispersed. However, there are some issues regarding the different nature of M2M communication and $\mathrm{H} 2 \mathrm{H}$ communication cellular networks are designed for the latter. Even the latest technology of cellular communication, named Long Term Evolution (LTE), is designed to cope with large data range requirements for only a small number of devices. By contrast, when investigating the characteristics of M2M communication, it can be found out that here the situation is quite different. There is a vast number of devices generating sporadic transitions of short packets, and this can overload or even shut down such a network. Furthermore, the signals and commands in M2M communication may be very sensitive to delays. Therefore, if cellular networks are to be considered as an optimal communication protocol for smart inverters they still need further improvements. As a matter of fact, the 3GPP became concerned about these issues and is currently aiming to incorporate the requirements of M2M communications in the development of the next generation of LTE or 5G [49-52].

In addition to cellular networks, there are other wireless communication technologies available. Extremely short-range technologies such as Near-field Communication (NFC) are mostly useless for inverters. Nevertheless, other short-range active radio frequency systems, such as Bluetooth or the IEEE 802.15.4 standard-based family like ZigBee and 6LoWPAN can be an alternative in some cases [49,53]. Moreover, low-power wide area networks (LPWANs) offer many of the desired features for M2M communication applications. Among the examples in this category, LoRa technology can be considered for the application to microgrids due to its low implementation and operational cost and relatively long range [49,54-56]. A comparison of these different methods is summarized in Table 2.

For M2M communication applications, the literature review highlighted ZigBee and LPWAN as the standards of choice. Comparing their specifications in Table 2, it can be observed that ZigBee provides a sufficient data rate but at the same time it has a very short range [49]. In contrast, LPWAN technologies demonstrate the opposite behavior. One of the reasons for this is the different network topologies. ZigBee systems are usually implemented following a mesh topology that provides the benefit of fault tolerance but makes the routing process more complex and not energy efficient. Furthurmore, because of the multi-hop nature of mesh network topology the actual data rate might decrease dramatically to the point that it may no longer be suitable for the application of M2M communication [49]. On the other hand, the LPWANs, or specifically LoRa and SIGFOX, networks have star topology with central nodes connecting to the internet. This topology can help with the overall simplicity of the system and less power consumption of each node. However, if a failure happens to one of the principal nodes then other nodes cannot compensate for and keep the network active [53]. Figure 2 is an illustration of the mesh (a) and star (b) topologies described before. In some countries, LPWANs technologies use cellular network bandwidths, and according to the availability and robustness of those, it can be very beneficial. Nevertheless, both short and long-range technologies have the ability to perform in unlicensed bandwidths. This is mostly an economic consideration 
although it may reduce the quality and security of the protocol at the same time $[49,62]$. Figure 3 represents a comparison of different wireless technologies based on range and data rate.

Table 2. Comparison of different wireless technologies for M2M communication.

\begin{tabular}{|c|c|c|c|c|c|}
\hline \multicolumn{2}{|c|}{ Technology } & Data Rate & Coverage & Disadvantages & References \\
\hline & GSM & Max $14.4 \mathrm{Kbps}$ & $1-10 \mathrm{Km}$ & Data rates low & \multirow{4}{*}{ [35] } \\
\hline Cellular & GPRS & Max $170 \mathrm{Kbps}$ & $1-10 \mathrm{Km}$ & Data rates low & \\
\hline network & $3 G$ & Max 2 Mbps & $1-10 \mathrm{Km}$ & High cost & \\
\hline & WIMAX & Max 75 Mbps & $\operatorname{Max} 50 \mathrm{Km}$ & Availability limited & \\
\hline \multirow{5}{*}{ Short range } & ZigBee & $250 \mathrm{Kbps}$ & Approx $50 \mathrm{~m}$ & Short range and low data rate & \multirow{5}{*}{$\begin{array}{c}{[35,49,57]} \\
{[58]} \\
{[49,59]} \\
{[49,57,59]}\end{array}$} \\
\hline & 6LoWPAN & $250 \mathrm{Kbps}$ & $10-100 \mathrm{~m}$ & Short range and low data rate & \\
\hline & Bluetooth & $1-2 \mathrm{Mbps}$ & $15-30 \mathrm{~m}$ & Short range & \\
\hline & Wi-Fi & $54 \mathrm{Mb} / \mathrm{s}$ & $100 \mathrm{~m}$ & Short range & \\
\hline & UWB & $110 \mathrm{Mb} / \mathrm{s}$ & $10 \mathrm{~m}$ & Very short range & \\
\hline \multirow{4}{*}{ LPWAN } & LoRa & $0.3-37.5 \mathrm{Kbps}$ & $\begin{array}{c}\text { 3-5 Km (Urban) } \\
10-15 \mathrm{Km} \text { (Rural) }\end{array}$ & Low data range & \multirow{4}{*}[49,60,61]{} \\
\hline & SIGFOX & 01 Khns & 3-10 Km (Urban) & & \\
\hline & SIGFUג & 0.1 Kops & 30-50 Km (Rural) & Low data range & \\
\hline & eMTC & Less than $1 \mathrm{Mbps}$ & $\begin{array}{l}5 \mathrm{~km} \text { (urban) } \\
17 \mathrm{~km} \text { (rural) }\end{array}$ & Licensed network & \\
\hline
\end{tabular}



(a)

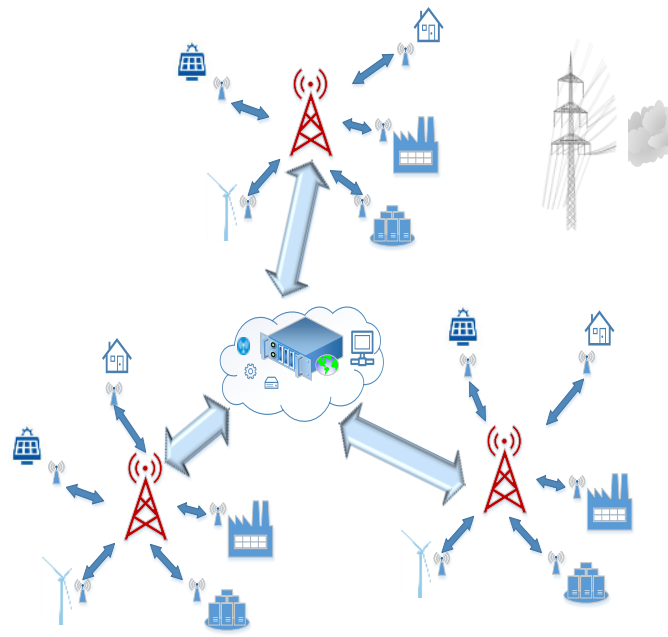

(b)

Figure 2. A schematic illustration of (a) the mesh topology of ZigBee and (b) the start topology of LoRa communication protocols.

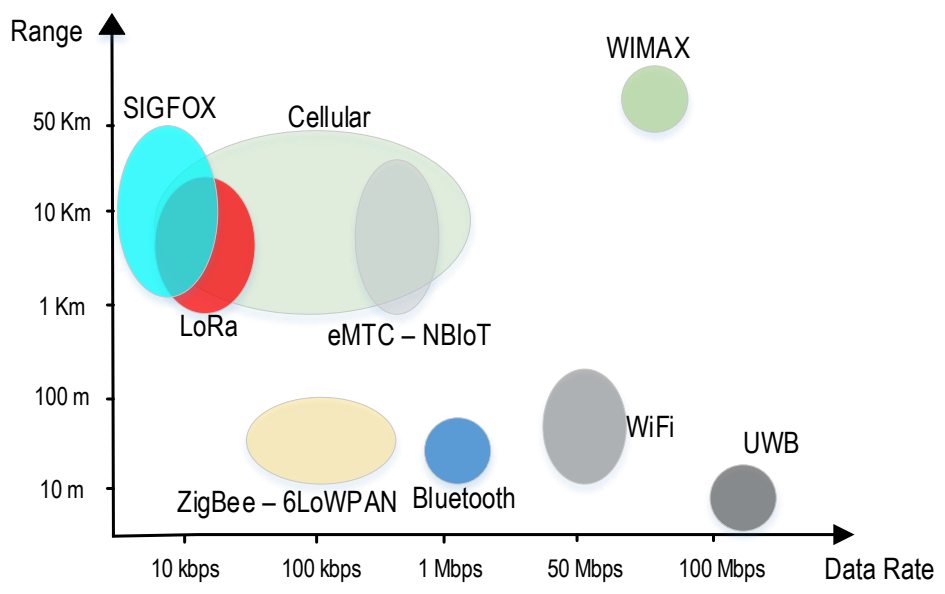

Figure 3. Comparison of different wireless technologies based on range and data rate. 


\subsection{Self-Awarness}

In the definition of smart inverter, self-awareness is another key concept to be considered. In simple words, this means that the inverter is aware of its possible faulty parts, can determine their exact location, work out the cause of the fault, and be able to isolate them. In addition, the ability to predict possible future fault occurrences to program preventive maintenance is essential. Self-awareness can be divided into three different, yet closely related concepts $[34,63,64]$ :

- Diagnostics so the inverter finds out the reason and origin of a fault after the occurrence.

- Condition monitoring $(\mathrm{CM})$ which is a real-time evaluation of the component health status.

- Prognosis to estimate if a fault is going to happen in the future and when.

These three methods rely on fault detection procedures. For diagnostics, it is obvious that in order to work out the reason for a fault, at first, it needs to happen and be detected. For CM and prognosis, a fault or an initiation of a fault needs to be located in order to prevent the complete system to shut down or even worse. However, there are several challenges accompanied by this procedure. One problem is the effect of continuous measurements. The three concepts require measurements and it is a well-known fact that measurements cannot always be taken without interrupting the normal operation of the device. In addition, the process of deriving health indicators from physical measurements and furthermore extract prediction indicators from them can be complex $[63,64]$.

Inverter faults are mostly triggered by thermomechanical fatigue in IGBTs [65]. They are commonly classified as, open-circuit faults, short-circuit faults and intermittent gate signal $[66,67]$. Detecting short-circuit faults can be easy, since in case of an occurrence, the current will rise to about four or five times the normal value. Therefore, traditional relays can be effective enough to detect and shut down the faulty component. However, the case is very different in open circuit faults, since the increase in current is not that significant, and if the sensitivity of the relays is reduced to the point they can sense these small current fluctuations, false tripping will also occur $[68,69]$. The intermittent behavior of RES can also cause false alarms if relays are being used for open-circuit fault detection [68]. Normally, open-circuit faults do not trigger a system shutdown but they cause the system to misbehave or work less efficient. Therefore, they can remain undetected for a long operational time resulting to other faults and further damages to the inverter [67]. As an outcome, it can be stated that open-circuit faults cannot be detected by hardware. However, there are several methods and algorithms available to effectively detect them.

In general, open circuit fault detection has been categorized into current-based methods and voltage-based methods [70]. One of the pioneering approaches in the first category is Park's vector method proposed in [71]. In this method, by applying Park vector transformation on the calculated average 3-phase current, the angle and magnitude of the currents in the complex domain are obtained, and by using pattern algorithms to analyze the trajectory of the space vector deviations, a fault can be identified. The complexity of this method is its main drawback $[67,69]$. In addition, this current based method and other similar ones in this category, such as two methods proposed in [72], contain another disadvantageous behavior which is a full one fundamental period delay between the occurrence and the actual detection [73]. Using voltage measurements is another criterion. Here the actual voltages at the key points of the circuit are measured and compared with their reference values derived by analytical models. This method is faster than the current based methods and the fault can be detected in one-fourth of a cycle but since voltage measurement devices are included, it adds to the complexity of the system $[69,70,73]$.

\subsection{Adaptability}

It is crucial for a smart component, in this case, a smart inverter, to be able to adapt or adjust itself to the changes and occurrences of the system in which it operates. This means the ability to estimate the parameters, specifically the impedance of the grid, and self-synchronize in terms of frequency. This is adaptability and is another crucial characteristic of a smart inverter. One of the 
most important operational problems of microgrids is unintended islanding. This is mainly due to grid failure, and the inverters are required to be included with islanding detection algorithms in order to be able to self-adapt if required. Furthermore, being fault tolerant is another operational ability that falls in this category [34]. The importance of fault-tolerant operation becomes relevant when it is not possible to partially or fully shut down a system due to its critical application even in faulty conditions. For example, hospitals require constant and stable electrical power, and if a fault occurs the grid is required to continue the supply until the problem is solved, otherwise it can cause devastating consequences [74].

\subsubsection{Fault Tolerance}

As an indication of system reliability, after a fault is detected, diagnosed and isolated, the inverter and consequently the whole system are required to continue normal operation. The diagnostics and isolation procedure is crucial to prevent the problem from propagating with possibly catastrophic consequences. To be able to continue to work under faulty conditions several methods are proposed, some of them are based on the implementation of extra hardware and modification in the topology and/or the modulation procedure [74,75]. These modifications are implemented on switch level, leg level, module level or device level. At all these levels, the fault tolerance characteristic is achieved by means of redundancy. Implementation of redundant hardware at leg level is a proposed solution. In case of a switch fault, the method proposed in [76] can replace the bidirectional switch traditionally installed in a matrix converter with any of the other nine switches. The principles of the leg level criteria are simple. When the fault occurs, and it has been diagnosed the switching signals of the semiconductors of that leg are removed and transferred to the redundant leg after the bidirectional switch connecting the leg to the main circuit is triggered. The timing of these switching and replacements are also important and require precision [77,78]. In [79], the implementation of extra hardware is not included, and the methods proposed used the inherent redundancy of multi-level inverter to achieve fault tolerance characteristic, this is an example of module level. Generally, the concept of modular level fault tolerance is to bypass the faulty semiconductor switch or switches, and the resulting decreased and often unbalanced output voltage is regulated by modifying the modulation method considering a phase shift in the voltage reference to provide a balanced line to line output voltages $[80,81]$. The device level, which is normally implemented at industrial applications, is to use a parallel redundant inverter.

\subsubsection{Islanding Detection}

Unintended islanding occurrence is inevitable but must be detected as fast as possible so the distributed system can be decoupled from the grid immediately. Otherwise, it can cause harm to line workers in the main grid or deviate the voltage and frequency from the standard level. Therefore, one of the characteristics of a smart inverter is being equipped with islanding detection methods. These methods are primarily divided into remote and local detection techniques.

Remote methods are based on the detection on the consumer side and require communication between the utility and the inverter. These methods are out of the scope of this study [82-84]. Local islanding detection methods, as their name indicates, perform the detection based on local measurements. They are divided into two categories, passive and active methods. Passive methods monitor the voltage variation, frequency deviation, rate of change of power, rate of change of frequency or other trends of the system. When islanding happens these parameters will vary and if this variation exceeds a defined threshold, then islanding is detected [84]. However, if the loading of the DG does not change significantly after an islanding situation takes place, then it cannot be detected by monitoring fundamental parameters such as voltage change or frequency deviation so utilizing other parameters such as voltage unbalance or total harmonic distortion (THD) has been proposed [85]. In [86] another method which utilizes the rate of change of frequency over power has been introduced. 
Active methods are based on the perturbation and later monitoring of the response of system. If unintended islanding occurs, the changes of parameters due to these perturbations will be considerable [82]. One variant of these methods is the impedance measurement method. Here, a harmonic current is injected and by monitoring the voltage response, the grid impedance can be measured. If this impedance changes for more than $0.5 \Omega$ it can be an indication of grid failure and the DG must be decoupled. This is a fast and cheap anti-islanding method, and the problem of intentionally adding to the system disturbances can be reduced by using the harmonic signal injection at higher frequencies, 400-600 Hz [87-89].

Naturally, both passive and active methods have advantages as well as drawbacks. Passive methods are fast and do not introduce harmonics and distortion. However, they are ineffective when the load and generation are closely matched at islanded mode and generally have larger none detection zone (NDZ). By contrast, the active methods are slower, introduce harmonics to the system and, therefore, the power quality is degraded, but at the same time, they present a decent detection possibility even if there is a perfect match between load and generation in islanded mode. In other words, the active methods contain a much smaller NDZ [82-84]. Figure 4 is an illustration of islanding detecting categories with a brief summary of their advantages and disadvantages.

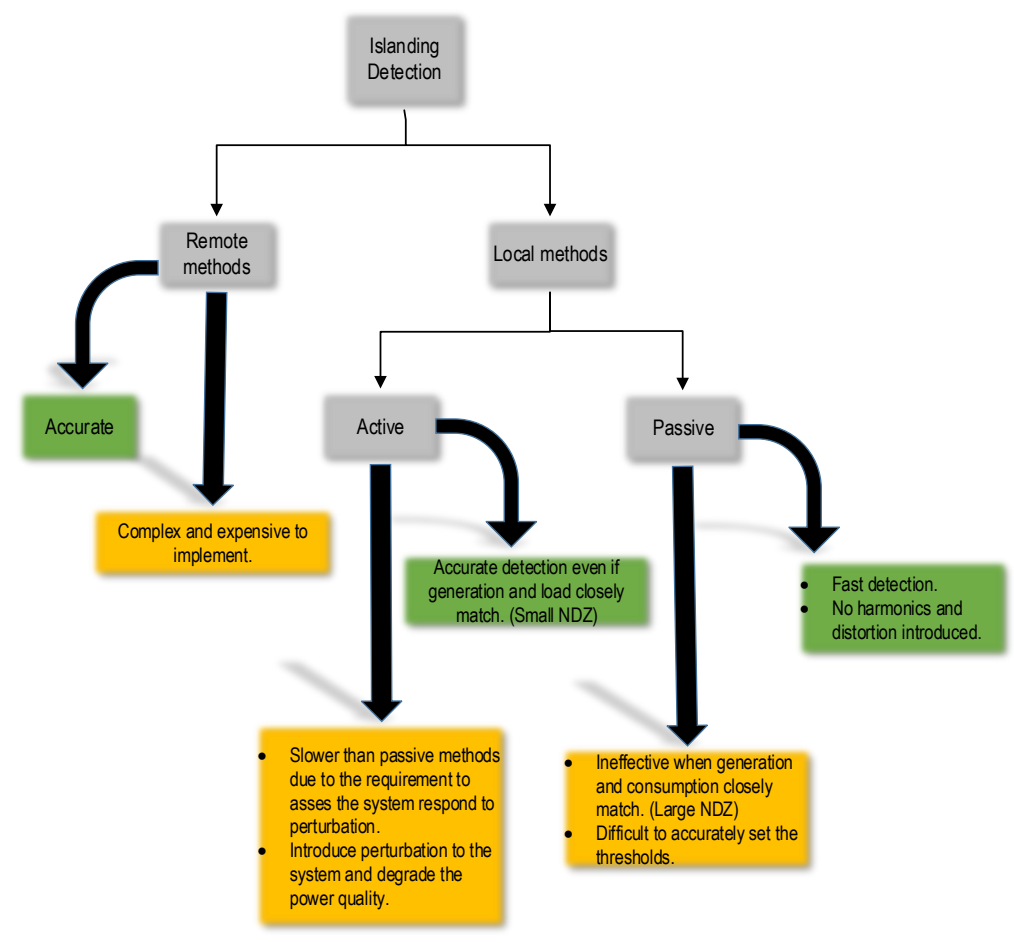

Figure 4. Islanding detection methods.

\subsection{Autonomy}

The different DGs and loads of a microgrid may be installed several kilometers apart, if not more. This means that the implementation of fast communication links to control every aspect of their operation is neither feasible nor cost-effective. On the other hand, the requirement of communication in microgrids cannot be completely omitted, but the inverters need to present some autonomous characteristics to be able to function properly. In this section, the most important autonomous features for smart inverters has been addressed. Control of the power flow using local measurements based on droop methods is explained briefly, as it is the foundation of the decentralized control idea. In addition, the mode flexibility feature is described. The importance of this feature emerges from the fact that it is necessary for a smart inverter to be able to autonomously switch operating modes due to different microgrid configurations. 


\subsubsection{Decentralized Power Control}

An inverter, as an interface for a DG, is required to be equipped with control schemes to control its active and reactive power flow autonomously. One method is using droop control schemes, which can control active and reactive power sharing effectively for parallel inverters only by using local measurements. These methods have been conventionally used for large power systems based on synchronous generators and gradually became a well-established method for microgrids. Droop control methods and more comprehensive proposed structures based on these methods, such as hierarchical control, have been extensively reviewed and presented in the literature $[8,9,12-14,16,17$, 19,28,29,90-99]. By implementing droop control accurate power sharing between parallel connected inverters can be achieved with regard to their power ratings. In an AC microgrid $P-\omega$ and $Q-V$ droops are being used for this purpose. The active and reactive output power can be calculated by local voltage-current measurements from low-pass filters. Then by using the droop Equations (1) and (2) and using the no-load values for $\omega_{0}$ and $V_{0}$, grid values for $V$ and $\omega$ can be worked out:

$$
\begin{gathered}
\omega=\omega_{0}-m P, \\
V=V_{0}-n Q,
\end{gathered}
$$

It shall be noted that in Equations (1) and (2) $P$ and $Q$ are the active and reactive delivered powers of each inverter, so the total power consumed by the loads is $P=P_{1}+P_{2}+\cdots$ and the same for reactive power. $m$ and $n$ are droop coefficients, and in simple droop, they are calculated in a way that they take the power rating of each component into effect:

$$
\begin{aligned}
& m_{1} S_{1}=m_{2} S_{2}=\cdots, \\
& n_{1} S_{1}=n_{2} S_{2}=\cdots,
\end{aligned}
$$

In Equations (3) and (4) $S$ values are the apparent power ratings of each DGs. By solving Equations (1) and (2) the reference voltage can be extracted that will be used by the inverters inner control loops to regulate its power flow. In other words, the droop control provides references for the inner control loops of the inverter. In more complex control schemes, which consist of more than one layer of control, the secondary control compensates for the frequency and voltage deviation resulted from the droop control. This means that it transmits voltage and frequency references for the primary level (droop). The droop coefficients are also influenced by energy management consideration of higher levels of control, tertiary level of hierarchical control [13]. Figure 5 illustrates the droop control concept for active power including the secondary control effect.

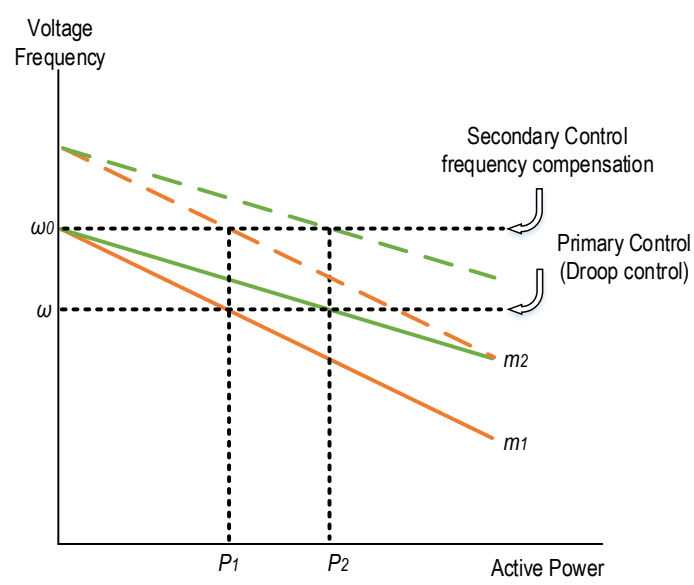

Figure 5. Illustration of active power sharing between two parallel inverters using conventional droop method. The secondary response of the hierarchical control is also included. 


\subsubsection{Mode Flexibility}

Another autonomous feature for an inverter is its ability to change its operational mode without external intervention in a smooth and seamless way. Depending on the control structure, an inverter can operate as grid forming, grid feeding and grid supporting [10]. In grid-connected mode, since the parameters are set by the grid the inverters perform as either grid feeding or grid supporting. By contrast, in islanded mode, there must be at least one grid forming inverter setting the voltage and frequency references of the grid. Figure 6 is a representation of these different configurations. As it can be observed in Figure 6a, the grid forming inverter functions as an ideal voltage source with fixed voltage and frequency. The additional loop (in green) is a descriptive illustration of voltage base grid supporting inverter or VSI. The control structure of these inverters is designed to work out the active and reactive power flow of each inverter and by using different control schemes provide voltage and frequency references. Figure $6 \mathrm{~b}$ presents the same concept for grid feeding inverters and CSIs, which inject fixed or variable active and reactive power according to their inner loops and MPPT algorithms if they are of renewable energy nature [100].

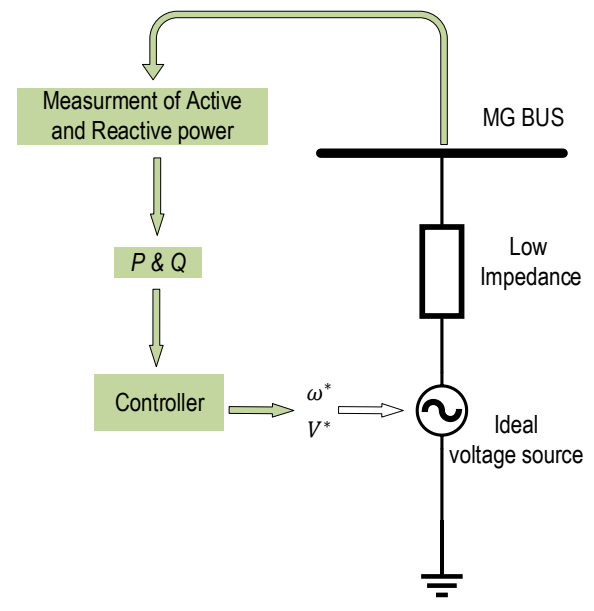

(a)

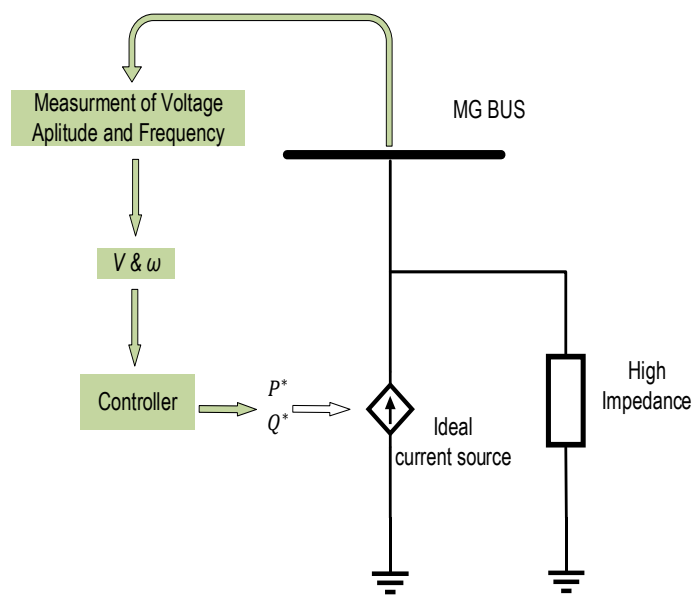

(b)

Figure 6. Representation of different modes of inverters in microgrids. (a), grid forming/grid supporting VSI, (b), grid feeding/grid supporting CSI.

The concern here is the transition state when inverters roles are switched between these different modes. This switching is required due to the transition of the state of the microgrid from grid connected to islanded or the other way around. One side effect of this phenomenon is frequency unbalances and voltage and current disturbances so the inverters are required to be equipped with suitable control schemes the be able to compensate for these transient effects and provide a smooth transient state $[94,101-104]$.

In [103] a method has been proposed consisting of a phase-locked-loop (PLL) in order to retrieve the inverters output voltage angle and use it as a reference for droop control. In addition, a virtual inductor is used to limit the current inrush. Therefore, a smooth transition mode can be achieved. There are other approaches using a similar idea, based on PLL controllers. For instance, in [105] a method with the capability of ensuring a smooth transition in booth direction, grid connected to islanded and islanded to grid connected, has been proposed. Another method gathers voltage samples from grid and point of common coupling (PCC) at islanded mode, the values can be fed to a synchronization controller and after that been introduced to the droop control scheme, as reference values, which is regulating voltage and frequency at islanded mode. In this manner, a seamless mode transition is achieved after synchronization [106]. 


\subsection{Cooperativeness}

An inverter, as a part of a grid, is required to function according to the functionality of other components of the grid. This is cooperativeness. One of the major aspects in this area is power sharing, which has been addressed before by introducing hierarchical droop based controls. However, by implementing the conventional droop, although active power sharing can be sufficiently achieved by using local measurements, reactive power sharing is not that accurate and also the problem of harmonics current sharing is not addressed. Furthermore, there are other aspects such as ramp rate control for renewable energy sources and soft start capability, which lie in this category.

\subsubsection{Reactive Power and Harmonic Current Sharing}

The problem of reactive power sharing inaccuracy in conventional droop methods is derived from the fact that it depends on the impedance of DG feeders and out-put side impedance of L-C-L filters. This contrasts with the active power sharing control, which is always accurate. In order to overcome this problem, several techniques have been proposed. The first group of methods are based on introducing a virtual impedance loop in order to compensate for the inverter output and line impedance unbalances and therefore improving the reactive power sharing. Several approaches based on this idea can be found in the literature, and their sole drawback is due to the possible large value of the virtual impedance. This may degrade the voltage quality particularly in weak islanded microgrids [19,107-109]. The concept of virtual impedance loop can be described by the following equations:

$$
\vartheta_{0}=\vartheta_{0}^{*}-i_{0} Z_{0}(s),
$$

where $\vartheta_{0}$ is the voltage reference provided for inner control loops, $\vartheta_{0}^{*}$ is the voltage reference calculated by the droop control loop and $Z_{0}(s)$ is the virtual impedance transfer function. Same as the $m$ and $n$ droop coefficient calculations in Equations (3) and (4), $Z_{0}$ values for different units are calculated according to their power ratings:

$$
Z_{01} S_{1}=Z_{02} S_{2}=\cdots,
$$

Considering Equations (5) and (6) it can be understood that the virtual impedance implementation method generates a new voltage reference for inner control loops of the inverter by modifying the initial references set by the droop algorithms. Many approaches are conducted to empower the virtual impedance shaping technique. By using communication, the feeder impedance can be actively compensated, and this improves the reactive power sharing quality $[8,13]$. Modifying the droop method is another method to improve reactive current sharing Over the years, many improved techniques have been proposed and implemented [110,111]. In [110], an enhanced droop method has been proposed. In this method, the reactive power sharing is improved by the sharing error reduction operation. However, this procedure will cause an output voltage reduction which is regulated separately. Signal injection techniques can be mentioned as an example of other methods proposed for this purpose [112].

The sharing of harmonic currents generated because of the presence of non-linear loads, such as rectifiers, have not been addressed by conventional droop methods [107,113-115]. This presence of harmonics can affect the voltage and current wave-forms, cause overheating problems and add to losses, and lead to stability problems, therefore needed to be shared accurately [116,117]. In [108] a modification in the virtual impedance loop was proposed. This method provides the resistive output impedance for higher order current harmonics by subtracting the voltages corresponding to current harmonics from the reference voltage:

$$
\vartheta_{0}=\vartheta_{0}^{*}-i_{01} s L_{D}-\sum_{\substack{h=3 \\ \text { odd }}}^{11} i_{o h} R_{h}
$$


where $i_{01}$ is the output current, $L_{D}$ is the virtual impedance and $R_{h}$ is the resistive coefficient corresponding to each of the harmonic terms, $i_{\text {oh }}$ By using Equation (7), a new voltage reference is generated for the inner loops, covering effects of both linear and non-linear loads.

\subsubsection{Soft Start}

When a DG is initiating its energy generation, its interface inverter will try to start injecting power into the microgrid. If this procedure occurs without proper initiations, it will cause transient disturbances in grid parameters which are obviously not favorable. The ability of soft start for inverters can be achieved by modifying the virtual impedance loop. The soft starter controls the virtual impedance and is programmed to assign it with a higher value at the beginning of the transient state and then gradually reduce it to its nominal value. This is a modification for the virtual impedance loop mentioned before as part of the power sharing control (specifically to improve the reactive power and harmonic current sharing). Therefore as the control structure is already equipped with a virtual impedance loop it is just required to include the soft starter $[94,99,118,119]$. The implementation of the soft starter is done by the following Equation (8):

$$
Z_{D}(t)=Z_{f}-\left(Z_{f}-Z_{i}\right) e^{\frac{-t}{T}},
$$

where $Z_{f}$ and $Z_{i}$ are the initial and final values of the virtual impedance and $T$ is the time interval of the soft start procedure. By using this method, the system can start with a large impedance and gradually decrease it to its designed value for normal operation $[13,120,121]$.

\subsubsection{Ramp Rate Control}

DGs in microgrids are mostly of a renewable energy nature and it is a well-known fact that these type of energies, specifically wind and solar, suffer fluctuations in their power generation due to climate-caused effects. These power ramp rates are required to be controlled in a defined boundary in order to reduce the risk of possible damage occurrences when for example the clouds suddenly clear out over a large solar power station. The concept of ramp rate control is simple and can be represented by a simple equation for a solar panel $[122,123]$ as in Equation (9):

$$
R(t)=\frac{d P_{P V}}{d t}=\frac{\Delta P}{\Delta T},
$$

where $R(t)$ is the instant ramp rate, and $P_{P V}$ is the instant power generated by the panel. When the ramp rate exceeds a defined value, the output power requires to be regulated. Incorporating energy storage units such as batteries, flywheels and supercapacitors or reliable energy generation units such as fuel cells are the common methods to compensate for these fluctuations and smoothen the generation [124-127]. Using Equation (10), the energy storage capacity required for ramp rate control according to the power rating/perimeter scale of a solar field and the maximum acceptable ramp rate value can be worked out $[128,129]$ :

$$
\begin{gathered}
C_{E S S}=\frac{1.8 P^{*}}{3600}\left[\frac{90}{2 R_{\max }}-\tau\right], \\
\tau=a \cdot l+b,
\end{gathered}
$$

where $C_{E S S}$ is the capacity of the energy storage unit, $R_{\max }$ is the maximum ramp rate and $P^{*}$ is the power of the solar field. Equation (11) represents the time constant $\tau$, which is an empirical correlation with the shortest measured length of the solar field perimeter, $l$. ( $a=0.042 \mathrm{~s} / \mathrm{m}$ and $b=-0.5 \mathrm{~s})$. In [124] implementation of electric double layer capacitor (EDLC) for smoothening the generation of PV panels alongside with the size consideration of the capacitor and the utilization of a fuel cell to compensate for slow generation fluctuations have been discussed. Although most of the ramp rate 
control methods are based on using energy storage devices, there are other possibilities. For example, In [122], by modifying the MPPT algorithms, which renewable energy systems functions are based on, the ramp rate can be controlled by deviating from the set point of the MPPT when required, to balance the output power.

\section{Discussion}

In order to define a device as smart, it has to represent several qualities and characteristics mostly depending on its application and implementation. In this study, these characteristics have been described for inverters, which are used as interfaces for DGs in microgrids:

- Plug-and-play capability has been the first concept discussed. Regardless of how much effort has been expended to omit the communication requirement, in order to achieve a stable and functional microgrid, especially in the context of accurate active, reactive and harmonic current sharing, this requirement still exists. In contrast to other smartness indicators that evaluate the smartness based on how less it relies on communication for normal operation, plug-and-play is mainly related to communication compatibility. Different relevant communication technologies have been introduced and investigated in detail with tabular information. The fact that the DGs can be spread over a large area, maybe several kilometers apart, will emphasize the infeasibility of using conventional communication protocols mostly according to economic considerations. One practical and attractive solution can be the use of the Internet. However, in accordance with M2M communication and the Internet of things concept, it is not practical to connect every node of a system directly to the web. A long range, low implementation and operating cost, protocol that is reliable enough at the same time, such as LoRa or ZigBee, can be used to communicate each of the inverters to internet gateways. It is understood, further research and thorough experimental work are required to end up with a conclusion and chose one communication protocol over another.

- Self-awareness is another smartness indicator. In this section, the concept of fault diagnosis, condition monitoring and prognosis have been explained. In addition, fault detection methods have been briefly reviewed since all three-health indicators of inverters require fault detection at some point in their control structure. According to various methods proposed for open-circuit fault detection, it can be observed that, no matter how complicated the detection algorithm could be, there are still based on local measurements with the aim of avoiding the further requirement of communication. Short-circuit fault detection can be effectively conducted by use of hardware and local current measurements.

- Another studied characteristic of smart inverters has been their adaptability. This is related to the change of parameters of the grid, the loads and the working mode of the inverter itself. Here smartness is the ability to sense and identify some fluctuations in the parameters readings that can be an indication for faults. Then, effectively self-adjust to be able to continue to function regardless of the mode change or the fault as it is not always possible to shut down the system immediately even if a serious problem has been detected. This is called fault tolerance, and the different methods have been introduced and compared. Some of them require extra, redundant, hardware and others provide redundancy by manipulating the modulation process. Unintended islanding for microgrids due to grid failure is another issue, and if the system cannot self-adapt itself with this phenomenon, the results can be catastrophic. Methods for islanding detection are different, and they have been briefly introduced and compared. It is understood, same as the fault detection methods, in islanding detection methods the aim of reducing communication requirements and self-adapting in the procedure is a major consideration nowadays.

- The other important characteristic is autonomy, which intends to reduce the requirements for communications among inverters installed far away from each other even more. In microgrids, depending on if it is islanded or grid-connected, the inverters are controlled as VSCs or CSCs connected in parallel. One measure of autonomy is the ability to control the active and reactive power sharing among them with minimum required communication. The droop control methods 
empower this characteristic by controlling each DGs power flow according to its rated values, by mostly using local measurements to minimizing communication requirements. Another aspect that has been considered here is when the working mode of the microgrid changes from islanded to grid-connected or vice versa. Naturally, in that case, the role of most inverters is required to be changed as well, since in islanded mode the inverters are mostly controlled as grid forming, in contrast to a grid-connected mode when they transform to grid feeding or grid supporting modes. These transformations are required to be done automatically, and each of the inverters should be equipped with suitable control structures to make these mode switching accompanied by unavoidable transient responses seamless and smooth.

- The last concept covered has been cooperativeness. By definition, this means the smartness that an inverter requires to be able to function in accordance and alongside with other inverters in a grid. All the inverters are required to take some responsibility to regulate and compensate for unbalances and disturbances present in the system. In addition, their operation and behavior should be in alignment with other neighboring components. Otherwise, further disturbances will be introduced to the system. Active, reactive and harmonics current sharing is the most important characteristic fitting in this definition. In contrast to some of the characteristics discussed before the requirement of communication can be sensed for cooperativeness.

As a brief summary of the concepts addressed above it can be stated that smartness of an inverter in a microgrid, mostly refers to minimizing communication requirements for its normal operation. However, according to the current literature, this requirement is still present and cannot be omitted altogether. Currently, different communication protocols are used for this application, as well as other M2M communication applications, but each of them have their own drawbacks and are far from perfect. Therefore, there is a broad area of research and development available to fill this gap. One possible idea is the use of the Internet infrastructure which sounds perfect according to its worldwide availability and its great storage and computational potentials based on the cloud concept. Nevertheless, here, the most important consideration is not the internet platform itself. On the contrary, the main aspect is to propose an architecture to connect the components to the cloud. Such an architecture is required to present these qualities:

- Reliable; no data can be lost or misinterpreted.

- Fast, thresholds for delays are very limited.

- Secure, immune from unregistered intervention.

- Globally available and compatible.

- Low energy consumption.

- Robustness.

- Bidirectional.

- Economically feasible, in terms of implementation, operational costs and maintenance.

Containing these characteristics, a structure based on a wireless communication protocol can be proposed for inverters communication to improve microgrids performance and control. In spite of that, it should always be remembered that every communication structure, no matter how carefully engineered and well established it is, still contain deficiencies such as delays, by nature. Therefore, the research and development of control structures centered on the goal of reducing the communication requirement should continue further more.

Author Contributions: B.A.-Z. carried out the literature review and wrote the paper; E.J.P.-G. supervised and provided critical reviews. J.C.V. and J.M.G. coordinated and reviewed the final work.

Funding: This research was funded by the Aalborg University Talent Programme 2016 with the research project: The Energy Internet-Integrating Internet of Things into the Smart Grid.

Acknowledgments: This work was funded by the AAU Talent Project: The Energy Internet-Integrating Internet of Things into the Smart Grid (http:/ / www.iot-energy.et.aau.dk). 
Conflicts of Interest: The authors declare no conflict of interest.

\section{References}

1. Colson, C.M.; Nehrir, M.H. A review of challenges to real-time power management of microgrids. In Proceedings of the 2009 IEEE Power \& Energy Society General Meeting, Calgary, AB, Canada, 26-30 July 2009; pp. 1-8.

2. Pepermans, G.; Driesen, J.; Haeseldonckx, D.; Belmans, R.; D’haeseleer, W. Distributed generation: Definition, benefits and issues. Energy Policy 2005, 33, 787-798. [CrossRef]

3. Lasseter, R.; Piagi, P. Microgrid: A Conceptual Solution. In Proceedings of the 2004 IEEE 35th Annual Power Electronics Specialists Conference, Aachen, Germany, 20-25 June 2004.

4. Marnay, C.; Chatzivasileiadis, S.; Abbey, C.; Iravani, R.; Joos, G.; Lombardi, P.; Mancarella, P.; Von Appen, J. Microgrid evolution roadmap. In Proceedings of the 2015 International Symposium on Smart Electric Distribution Systems and Technologies, Vienna, Austria, 8-11 September 2015; pp. 139-144.

5. Carrasco, J.M.; Garcia Franquelo, L.; Bialasiewicz, J.T.; Galván, E.; Portillo Guisado, R.C.; Martín Prats, M.D.L.Á.; León, J.I.; Moreno-Alfonso, N. Power-Electronic Systems for the Grid Integration of Renewable Energy Sources: A Survey. IEEE Trans. Ind. Electron. 2004, 53, 1002-1016. [CrossRef]

6. Prodanović, M.; Green, T.C. Control and filter design of three-phase inverters for high power quality grid connection. IEEE Trans. Power Electron. 2003, 18, 373-380. [CrossRef]

7. Zhong, Q.C.; Weiss, G. Synchronverters: Inverters that mimic synchronous generators. IEEE Trans. Ind. Electron. 2011, 58, 1259-1267. [CrossRef]

8. Guerrero, J.M.; Chandorkar, M.; Lee, T.L.; Loh, P.C. Advanced control architectures for intelligent microgridspart i: Decentralized and hierarchical control. IEEE Trans. Ind. Electron. 2013, 60, 1254-1262. [CrossRef]

9. Guerrero, J.M.; Loh, P.C.; Lee, T.L.; Chandorkar, M. Advanced control architectures for intelligent microgridsPart II: Power quality, energy storage, and AC/DC microgrids. IEEE Trans. Ind. Electron. 2013, 60, 1263-1270. [CrossRef]

10. Rocabert, J.; Luna, A.; Blaabjerg, F.; Rodríguez, P. Control of power converters in AC microgrids. IEEE Trans. Power Electron. 2012, 27, 4734-4749. [CrossRef]

11. Kim, J.; Guerrero, J.M.; Rodriguez, P.; Teodorescu, R.; Nam, K. Mode adaptive droop control with virtual output impedances for an inverter-based flexible AC microgrid. IEEE Trans. Power Electron. 2011, 26, 689-701. [CrossRef]

12. Lu, X.; Guerrero, J.M.; Sun, K.; Vasquez, J.C. An improved droop control method for dc microgrids based on low bandwidth communication with dc bus voltage restoration and enhanced current sharing accuracy. IEEE Trans. Power Electron. 2014, 29, 1800-1812. [CrossRef]

13. Guerrero, J.M.; Vasquez, J.C.; Matas, J.; De Vicuña, L.G.; Castilla, M. Hierarchical control of droop-controlled $\mathrm{AC}$ and DC microgrids-A general approach toward standardization. IEEE Trans. Ind. Electron. 2011, 58, 158-172. [CrossRef]

14. Yang, N.; Paire, D.; Gao, F.; Miraoui, A.; Liu, W. Compensation of droop control using common load condition in DC microgrids to improve voltage regulation and load sharing. Int. J. Electr. Power Energy Syst. 2015, 64, 752-760. [CrossRef]

15. Alsafran, A. Literature Review of Power Sharing Control Strategies in Islanded AC Microgrids with Nonlinear Loads. In Proceedings of the 2018 IEEE PES Innovative Smart Grid Technologies Conference Europe (ISGT-Europe), Sarajevo, Bosnia-Herzegovina, 21-25 October 2018; pp. 1-6.

16. Guerrero, J.M.; de Vicuna, L.G.; Matas, J.; Castilla, M.; Miret, J. A wireless controller to enhance dynamic performance of parallel inverters in distributed generation systems. IEEE Trans. Power Electron. 2004, 19, 1205-1213. [CrossRef]

17. Kim, J.W.; Choi, H.S.; Cho, B.H. A novel droop method for converter parallel operation. IEEE Trans. Power Electron. 2002, 17, 25-32.

18. Mihalache, L. Paralleling control technique with no intercommunication signals for resonant controller-based inverters. In Proceedings of the 38th IAS Annual Meeting on Conference Record of the Industry Applications Conference, Salt Lake City, UT, USA, 12-16 October 2003; Volume 3, pp. 1882-1889. 
19. Guerrero, J.M.; de Vicuna, L.; Matas, J.; Castilla, M.; Miret, J. Output Impedance Design of Parallel-Connected \{UPS\} Inverters With Wireless Load-Sharing Control. IEEE Trans. Ind. Electron. 2005, 52, 1126-1135. [CrossRef]

20. Converters, T.; Borup, U.; Blaabjerg, F.; Member, S.; Enjeti, P.N. Sharing of Nonlinear Load in Parallel-Connected. IEEE Trans. Ind. Appl. 2001, 37, 1817-1823.

21. Chang, J.M. Parallel operation of series-connected PWM voltage regulators without control interconnection. Proc. IEEE-Electr. Power Appl. 2001, 148, 141-147. [CrossRef]

22. Chiang, S.J.; Yen, C.Y.; Chang, K.T. A Multimodule Parallelable Series-Connected. IEEE Trans. Ind. Electron. 2001, 48, 506-516. [CrossRef]

23. Song, S.H.; Kang, S.I.; Hahm, N.K. Implementation and control of grid connected AC-DC-AC power converter for variable speed wind energy conversion system. In Proceedings of the Eighteenth Annual IEEE Applied Power Electronics Conference and Exposition, Miami Beach, FL, USA, 9-13 February 2003; pp. 154-158.

24. Kim, J.S.; Sul, S.K. New control scheme for AC-DC-AC converter without DC link electrolytic capacitor. In Proceedings of the IEEE Power Electronics Specialist Conference, Seattle, WA, USA, 20-24 June 1993; pp. 300-306.

25. Kakigano, H.; Miura, Y.; Uchida, R.; Engineering, I. DC Micro-grid for Super High Quality Distribution. IEEE Power Electron. Spec. Conf. 2010, 25, 3066-3075. [CrossRef]

26. Salomonsson, D.; Soder, L.; Sannino, A. An Adaptive Control System for a DC Microgrid for Data Centers. IEEE Trans. Ind. Appl. 2008, 44, 1910-1917. [CrossRef]

27. Che, L.; Shahidehpour, M. DC microgrids: Economic operation and enhancement of resilience by hierarchical control. IEEE Trans. Smart Grid 2014, 5, 2517-2526.

28. Bidram, A.; Davoudi, A. Hierarchical structure of microgrids control system. IEEE Trans. Smart Grid 2012, 3, 1963-1976. [CrossRef]

29. Nutkani, I.U.; Loh, P.C.; Wang, P.; Blaabjerg, F. Autonomous droop scheme with reduced generation cost. IEEE Trans. Ind. Electron. 2014, 61, 6803-6811. [CrossRef]

30. Photovoltaics, D.G.; Storage, E. IEEE Standard for Interconnection and Interoperability of Distributed Energy Resources with Associated Electric Power Systems Interfaces. In IEEE Std 1547-2018 (Revision IEEE Std 1547-2003); IEEE: Piscataway, NJ, USA, 2018; pp. 1-138.

31. Hoke, A.; Giraldez, J.; Palmintier, B.; Ifuku, E.; Asano, M.; Ueda, R.; Symko-Davies, M. Setting the Smart Solar Standard: Collaborations Between Hawaiian Electric and the National Renewable Energy Laboratory. IEEE Power Energy Mag. 2018, 16, 18-29. [CrossRef]

32. Mahmud, R.; Hoke, A.; Narang, D. Validating the test procedures described in UL 1741 SA and IEEE. In Proceedings of the 2018 IEEE 7th World Conference on Photovoltaic Energy Conversion (WCPEC), Waikoloa Village, HI, USA, 10-15 June 2018; pp. 1445-1450.

33. Behravesh, V.; Keypour, R.; Foroud, A.A. Stochastic analysis of solar and wind hybrid rooftop generation systems and their impact on voltage behavior in low voltage distribution systems. Sol. Energy 2018, 166, 317-333. [CrossRef]

34. Guerrero, J.M.; Xue, Y. Smart Inverters for Utility and Industry Applications. In Proceedings of the PCIM Europe 2015 International Exhibition and Conference for Power Electronics, Intelligent Motion, Renewable Energy and Energy Management, Nuremberg, Germany, 19-20 May 2015; pp. 277-284.

35. Supriya, S.; Magheshwari, M.; Sree Udhyalakshmi, S.; Subhashini, R. Musthafa Smart grid technologies: Communication technologies and standards. Int. J. Appl. Eng. Res. 2015, 10, 16932-16941.

36. Gungor, V.C.; Lu, B.; Hancke, G.P. Opportunities and challenges of wireless sensor networks in smart grid. IEEE Trans. Ind. Electron. 2010, 57, 3557-3564. [CrossRef]

37. Ancillotti, E.; Bruno, R.; Conti, M. The role of communication systems in smart grids: Architectures, technical solutions and research challenges. Comput. Commun. 2013, 36, 1665-1697. [CrossRef]

38. Kuzlu, M.; Pipattanasomporn, M.; Rahman, S. Communication network requirements for major smart grid applications in HAN, NAN and WAN. Comput. Netw. 2014, 67, 74-88. [CrossRef]

39. Kuzlu, M.; Pipattanasomporn, M.; Tech, V. Assessment of Communication Technologies and Network Requirements for Different Smart Grid Applications. In Proceedings of the IEEE PES Innovative Smart Grid Technologies Conference (ISGT), Washington, DC, USA, 24-27 February 2013.

40. Tankard, C. The security issues of the Internet of Things. Comput. Fraud Secur. 2015, 2015, 11-14. [CrossRef] 
41. Bekara, C. Security issues and challenges for the IoT-based smart grid. Procedia Comput. Sci. 2014, 34, 532-537. [CrossRef]

42. Galli, S.; Scaglione, A.; Wang, Z. For the grid and through the grid: The role of power line communications in the smart grid. Proc. IEEE 2011, 99, 998-1027. [CrossRef]

43. Yigit, M.; Gungor, V.C.; Tuna, G.; Rangoussi, M.; Fadel, E. Power line communication technologies for smart grid applications: A review of advances and challenges. Comput. Netw. 2014, 70, 366-383. [CrossRef]

44. Usman, A.; Shami, S.H. Evolution of communication technologies for smart grid applications. Renew. Sustain. Energy Rev. 2013, 19, 191-199. [CrossRef]

45. Galli, S.; Scaglione, A.; Wang, Z. Power Line Communications and the Smart Grid. In Proceedings of the 2010 First IEEE International Conference on Smart Grid Communications, Gaithersburg, MD, USA, 4-6 October 2010; pp. 303-308.

46. Kabalci, Y. A survey on smart metering and smart grid communication. Renew. Sustain. Energy Rev. 2016, 57, 302-318. [CrossRef]

47. Faheem, M.; Shah, S.B.H.; Butt, R.A.; Raza, B.; Anwar, M.; Ashraf, M.W.; Ngadi, M.A.; Gungor, V.C. Smart grid communication and information technologies in the perspective of Industry 4.0: Opportunities and challenges. Comput. Sci. Rev. 2018, 30, 1-30. [CrossRef]

48. Shaukat, N.; Ali, S.M.; Mehmood, C.A.; Khan, B.; Jawad, M.; Farid, U.; Ullah, Z.; Anwar, S.M.; Majid, M. A survey on consumers empowerment, communication technologies, and renewable generation penetration within Smart Grid. Renew. Sustain. Energy Rev. 2018, 81, 1453-1475. [CrossRef]

49. Centenaro, M.; Vangelista, L.; Zanella, A.; Zorzi, M. Long-range communications in unlicensed bands: The rising stars in the IoT and smart city scenarios. IEEE Wirel. Commun. 2016, 23, 60-67. [CrossRef]

50. Laya, A.; Alonso, L.; Alonso-Zarate, J. Is the random access channel of LTE and LTE-A suitable for M2M communications? A survey of alternatives. IEEE Commun. Surv. Tutor. 2014, 16, 4-16. [CrossRef]

51. Biral, A.; Centenaro, M.; Zanella, A.; Vangelista, L.; Zorzi, M. The challenges of M2M massive access in wireless cellular networks. Digit. Commun. Netw. 2015, 1, 1-19. [CrossRef]

52. Lien, S.Y.; Chen, K.C.; Lin, Y. Toward ubiquitous massive accesses in 3GPP machine-to-machine communications. IEEE Commun. Mag. 2011, 49, 66-74. [CrossRef]

53. Townsend, C.; Arms, S. Wireless sensor networks: Principles and aplications. In Sensor Technology Handbook; Wilson, J.S., Ed.; Elsevier: Amsterdam, The Netherlands, 2005; pp. 575-589.

54. Terashmila, L.K.A.; Iqbal, T.; Mann, G. A comparison of low cost wireless communication methods for remote control of grid-tied converters. In Proceedings of the Canadian Conference on Electrical and Computer Engineering, Windsor, ON, Canada, 30 April-3 May 2017; pp. 1-4.

55. Thielemans, S.; Bezunartea, M.; Steenhaut, K. Establishing transparent IPv6 communication on LoRa based low power wide area networks (LPWANS). In Proceedings of the 2017 Wireless Telecommunications Symposium (WTS), Chicago, IL, USA, 26-28 April 2017; pp. 1-6.

56. Angrisani, L.; Arpaia, P.; Bonavolonta, F.; Conti, M.; Liccardo, A. LoRa protocol performance assessment in critical noise conditions. In Proceedings of the 2017 IEEE 3rd International Forum on Research and Technologies for Society and Industry (RTSI), Modena, Italy, 11-13 September 2017.

57. Lee, J.; Su, Y.; Shen, C. A Comparative Study of Wireless Protocols: Bluetooth, UWB, ZigBee, and Wi-Fi. In Proceedings of the IECON 2007-33rd Annual Conference of the IEEE Industrial Electronics Society, Taipei, Taiwan, 5-8 November 2007; pp. 46-51.

58. Chen, Y.; Hou, K.M.; Zhou, H.; Shi, H.L.; Liu, X.; Diao, X.; Ding, H.; Li, J.J.; De Vaulx, C. 6LoWPAN stacks: A survey. In Proceedings of the 2011 7th International Conference on Wireless Communications, Networking and Mobile Computing, Wuhan, China, 23-25 September 2011; pp. 1-4.

59. Ferro, E.; Potortì, F. Bluetooth and Wi-Fi wireless protocols: A survey and a comparison. IEEE Wirel. Commun. 2005, 12, 12-26. [CrossRef]

60. Chen, J.; Hu, K.; Wang, Q.; Sun, Y.; Shi, Z.; He, S. Narrowband Internet of Things: Implementations and Applications. IEEE Internet Things J. 2017, 4, 2309-2314. [CrossRef]

61. Petäjäjärvi, J.; Mikhaylov, K.; Roivainen, A.; Hänninen, T.; Pettissalo, M. On the coverage of LPWANs: Range evaluation and channel attenuation model for LoRa technology. In Proceedings of the 2015 14th International Conference on ITS Telecommunications (ITST), Copenhagen, Denmark, 2-4 December 2016; pp. 55-59. 
62. Bardyn, J.P.; Melly, T.; Seller, O.; Sornin, N. IoT: The era of LPWAN is starting now. In Proceedings of the ESSCIRC Conference 2016: 42nd European Solid-State Circuits Conference, Lausanne, Switzerland, 12-15 September 2016; pp. 25-30.

63. Shaoyong, Y.; Dawei, X.; Angus, B.; Philip, M.; Li, R.; Peter, T. Condition Monitoring for Device Reliability in Power Electronic Converters: A Review. IEEE Trans. Power Electron. 2010, 25, 2734-2752.

64. Oh, H.; Han, B.; McCluskey, P.; Han, C.; Youn, B.D. Physics-of-failure, condition monitoring, and prognostics of insulated gate bipolar transistor modules: A review. IEEE Trans. Power Electron. 2015, 30, 2413-2426. [CrossRef]

65. Lamb, J.; Mirafzal, B. Open-Circuit IGBT Fault Detection and Location Isolation for Cascaded Multilevel Converters. IEEE Trans. Ind. Electron. 2017, 64, 4846-4856. [CrossRef]

66. Lu, B.; Sharma, S.K. A literature review of IGBT fault diagnostic and protection methods for power inverters. IEEE Trans. Ind. Appl. 2009, 45, 1770-1777.

67. Estima, J.O.; Cardoso, A.J.M. A new approach for real-time multiple open-circuit fault diagnosis in voltage-source inverters. IEEE Trans. Ind. Appl. 2011, 47, 2487-2494. [CrossRef]

68. Zeineldin, H.H.; Kan'an, N.H.; Casagrande, E.; Woon, W.L. Data mining approach to fault detection for isolated inverter-based microgrids. IET Gener. Transm. Distrib. 2013, 7, 745-754.

69. Moosavi, S.S.; Kazemi, A.; Akbari, H. A comparison of various open-circuit fault detection methods in the IGBT-based DC/AC inverter used in electric vehicle. Eng. Fail. Anal. 2019, 96, 223-235. [CrossRef]

70. An, Q.T.; Sun, L.Z.; Sun, L.; Jahns, T.M. Low-cost diagnostic method for open-switch faults in inverters. Electron. Lett. 2010, 46, 1021. [CrossRef]

71. Mendes, A.M.S.; Cardoso, A.J.M. Voltage Source Inverter Fault in Variable Speed Ac Current Approach. In Proceedings of the IEEE International Electric Machines and Drives Conference, Seattle, WA, USA, 9-12 May 1999; pp. 704-706.

72. Peuget, R.; Courtine, S.; Rognon, J.P. Fault detection and isolation on a pwm inverter. IEEE Trans. Ind. Appl. 1997, 34, 1471-1478.

73. De Araujo Ribeiro, R.L.; Jacobina, C.B.; Da Silva, E.R.C.; Lima, A.M.N. Fault detection of open-switch damage in voltage-fed PWM motor drive systems. IEEE Trans. Power Electron. 2003, 18, 587-593. [CrossRef]

74. Zhang, W.; Xu, D.; Enjeti, P.N.; Li, H.; Hawke, J.T.; Krishnamoorthy, H.S. Survey on fault-tolerant techniques for power electronic converters. IEEE Trans. Power Electron. 2014, 29, 6319-6331. [CrossRef]

75. Lezana, P.; Pou, J.; Meynard, T.A.; Rodriguez, J.; Ceballos, S.; Richardeau, F. Survey on fault operation on multilevel inverters. IEEE Trans. Ind. Electron. 2010, 57, 2207-2218. [CrossRef]

76. Andreu, J.; Kortabarria, I.; Ibarra, E.; Martínez De Alegría, I.; Robles, E. A new hardware solution for a fault tolerant matrix converter. In Proceedings of the 2009 35th Annual Conference of IEEE Industrial Electronics, Porto, Portugal, 3-5 November 2009; pp. 4469-4474.

77. Weber, P.; Poure, P.; Theilliol, D.; Saadate, S. Design of hardware fault tolerant control architecture for Wind Energy Conversion System with DFIG based on reliability analysis. In Proceedings of the 2008 IEEE International Symposium on Industrial Electronics, Cambridge, UK, 30 June-2 July 2008; pp. 2323-2328.

78. Rodríguez, M.A.; Claudio, A.; Theilliol, D.; Vela, L.G.; Hernández, L. Strategy to replace the damaged power device for fault-tolerant induction motor drive. In Proceedings of the 2009 Twenty-Fourth Annual IEEE Applied Power Electronics Conference and Exposition, Washington, DC, USA, 15-19 February 2009; Volume 52, pp. 343-346.

79. Li, S.; Xu, L. Strategies of fault tolerant operation for three-level PWM inverters. IEEE Trans. Power Electron. 2006, 21, 933-940. [CrossRef]

80. Yi, Z.; Hongge, S.; Bin, X. Optimization of neutral shift in cell-fault treatment for cascaded H-bridge. In Proceedings of the 2008 International Conference on Electrical Machines and Systems, Wuhan, China, 17-20 October 2008; pp. 1683-1685.

81. Correa, P.; Pacas, M.; Rodríguez, J. Modulation strategies for fault-tolerant operation of H-bridge multilevel inverters. IEEE Int. Symp. Ind. Electron. 2006, 2, 1589-1594.

82. Mahat, P.; Chen, Z.; Bak-Jensen, B. Review of Islanding Detection Methods for Distributed Generation. In Proceedings of the 2008 Third International Conference on Electric Utility Deregulation and Restructuring and Power Technologies, Nanjing, China, 6-9 April 2008; Volume 88, pp. 2743-2748. 
83. De Mango, F.; Liserre, M.; Dell'Aquila, A.; Pigazo, A. Overview of anti-islanding algorithms for PV systems. Part I: Passive methods. In Proceedings of the 2006 12th International Power Electronics and Motion Control Conference, Portoroz, Slovenia, 30 August-1 September 2007; pp. 1-6.

84. Li, C.; Cao, C.; Cao, Y.; Kuang, Y.; Zeng, L.; Fang, B. A review of islanding detection methods for microgrid. Renew. Sustain. Energy Rev. 2014, 35, 211-220. [CrossRef]

85. Kim, K.-H.; Jang, S.-I. An Islanding Detection Method for Distributed Generations Using Voltage Unbalance and Total Harmonic Distortion of Current. IEEE Trans. Power Deliv. 2004, 19, 745-752.

86. Pai, F.-S.; Huang, S.-J. A detection algorithm for islanding-prevention of dispersed consumer-owned storage and generating units. IEEE Trans. Energy Convers. 2001, 16, 346-351. [CrossRef]

87. Ciobotaru, M.; Teodorescu, R.; Blaabjerg, F. On-line grid impedance estimation based on harmonic injection for grid-connected PV inverter. In Proceedings of the 2007 IEEE International Symposium on Industrial Electronics, Vigo, Spain, 4-7 June 2007; pp. 2437-2442.

88. Asiminoaei, L.; Teodorescu, R.; Blaabjerg, F.; Borup, U. A digital controlled PV-inverter with grid impedance estimation for ENS detection. IEEE Trans. Power Electron. 2005, 20, 1480-1490. [CrossRef]

89. Asiminoaei, L.; Teodorescu, R.; Blaabjerg, F.; Borup, U. A new method of on-line grid impedance estimation for PV inverter. In Proceedings of the Nineteenth Annual IEEE Applied Power Electronics Conference and Exposition, Anaheim, CA, USA, 22-26 February 2004; pp. 1527-1533.

90. Hua, C.; Liao, K.; Lin, J.; City, T.; Country, Y. Parallel Operation of Inverters for Distributed Photovoltaic Power Supply System. In Proceedings of the 2002 IEEE 33rd Annual IEEE Power Electronics Specialists Conference, Cairns, Australia, 23-27 June 2002; pp. 1979-1983.

91. Simpson-Porco, J.W.; Dörfler, F.; Bullo, F. Synchronization and power sharing for droop-controlled inverters in islanded microgrids. Automatica 2013, 49, 2603-2611. [CrossRef]

92. Tuladha, A.; Jin, H.; Unger, T.; Mauch, K. Control of parrallel invertes in distribited AC power systems with considerartion of the line impedance effect. IEEE Trans. Ind. Appl. 1998, 36, 321-328.

93. Vasquez, J.C.; Guerrero, J.M.; Savaghebi, M.; Eloy-Garcia, J.; Teodorescu, R. Modeling, analysis, and design of stationary-reference-frame droop-controlled parallel three-phase voltage source inverters. IEEE Trans. Ind. Electron. 2013, 60, 1271-1280. [CrossRef]

94. Guerrero, J.M.; Vásquez, J.C.; Matas, J.; Castilla, M.; García de Vicuna, L. Control strategy for flexible microgrid based on parallel line-interactive UPS systems. IEEE Trans. Ind. Electron. 2009, 56, 726-736. [CrossRef]

95. Yu, X.; Khambadkone, A.M.; Wang, H.; Terence, S.T.S. Control of parallel-connected power converters for low-voltage microgrid-Part I: A hybrid control architecture. IEEE Trans. Power Electron. 2010, 25, 2962-2970. [CrossRef]

96. Yao, W.; Chen, M.; Matas, J.; Guerrero, J.M.; Qian, Z.M. Design and analysis of the droop control method for parallel inverters considering the impact of the complex impedance on the power sharing. IEEE Trans. Ind. Electron. 2011, 58, 576-588. [CrossRef]

97. Mohamed, Y.A.R.I.; El-Saadany, E.F. Adaptive decentralized droop controller to preserve power sharing stability of paralleled inverters in distributed generation microgrids. IEEE Trans. Power Electron. 2008, 23, 2806-2816. [CrossRef]

98. Zhong, Q.C. Robust droop controller for accurate proportional load sharing among inverters operated in parallel. IEEE Trans. Ind. Electron. 2013, 60, 1281-1290. [CrossRef]

99. Guerrero, J.M.; Matas, J.; De Vicuña, L.G.; Castilla, M.; Miret, J. Wireless-control strategy for parallel operation of distributed-generation inverters. IEEE Trans. Ind. Electron. 2006, 53, 1461-1470. [CrossRef]

100. Monshizadeh, P.; De Persis, C.; Monshizadeh, N.; Van Der Schaft, A. A communication-free master-slave microgrid with power sharing. In Proceedings of the 2016 American Control Conference (ACC), Boston, MA, USA, 6-8 July 2016; pp. 3564-3569.

101. Wang, J.; Chang, N.C.P.; Feng, X.; Monti, A. Design of a Generalized Control Algorithm for Parallel Inverters for Smooth Microgrid Transition Operation. IEEE Trans. Ind. Electron. 2015, 62, 4900-4914. [CrossRef]

102. Katiraei, F.; Iravani, M.R.; Lehn, P.W. Micro-grid autonomous operation during and subsequent to islanding process. IEEE Trans. Power Deliv. 2005, 20, 248-257. [CrossRef]

103. Hu, S.H.; Kuo, C.Y.; Lee, T.L.; Guerrero, J.M. Droop-controlled inverters with seamless transition between islanding and grid-connected operations. In Proceedings of the 2011 IEEE Energy Conversion Congress and Exposition, Phoenix, AZ, USA, 17-22 September 2011; pp. 2196-2201. 
104. Vandoorn, T.L.; Meersman, B.; De Kooning, J.D.M.; Vandevelde, L. Transition from islanded to grid-connected mode of microgrids with voltage-based droop control. IEEE Trans. Power Syst. 2013, 28, 2545-2553. [CrossRef]

105. Tran, T.V.; Chun, T.W.; Lee, H.H.; Kim, H.G.; Nho, E.C. PLL-based seamless transfer control between grid-connected and islanding modes in grid-connected inverters. IEEE Trans. Power Electron. 2014, 29, 5218-5228. [CrossRef]

106. Jin, C.; Gao, M.; Lv, X.; Chen, M. A seamless transfer strategy of islanded and grid-connected mode switching for microgrid based on droop control. In Proceedings of the 2012 IEEE Energy Conversion Congress and Exposition (ECCE), Raleigh, NC, USA, 15-20 September 2012; pp. 969-973.

107. He, J.; Li, Y.W.; Blaabjerg, F. An enhanced islanding microgrid reactive power, imbalance power, and harmonic power sharing scheme. IEEE Trans. Power Electron. 2015, 30, 3389-3401. [CrossRef]

108. Guerrero, J.M.M.; Matas, J.; Garcia de Vicuna, L.; Berbel, N.; Sosa, J. Wireless-Control Strategy for Parallel Operation of Distributed Generation Inverters. In Proceedings of the IEEE International Symposium on Industrial Electronics, Dubrovnik, Croatia, 20-23 June 2005; pp. 845-850.

109. Axelrod, B.; Berkovich, Y.; Ioinovici, A. Virtual Impedance Loop for Droop-Controlled Single-Phase Parallel Inverters Using a Second-Order. In Proceedings of the 2003 International Symposium on Circuits and Systems, Bangkok, Thailand, 25-28 May 2003; pp. 2993-3002.

110. Han, H.; Liu, Y.; Sun, Y.; Su, M.; Guerrero, J.M. An improved droop control strategy for reactive power sharing in islanded microgrid. IEEE Trans. Power Electron. 2015, 30, 3133-3141. [CrossRef]

111. Yaoqin, J.; Dingkun, L.; Shengkui, P. Improved droop control of parallel inverter system in standalone microgrid. In Proceedings of the 8th International Conference on Power Electronics-ECCE Asia, Jeju, Korea, 30 May-3 June 2011; pp. 1506-1513.

112. He, J.; Li, Y.W. An enhanced microgrid load demand sharing strategy. IEEE Trans. Power Electron. 2012, 27, 3984-3995. [CrossRef]

113. Vandoorn, T.; Meersman, B.; De Kooning, J.; Vandevelde, L. Controllable harmonic current sharing in islanded microgrids: DG units with programmable resistive behavior toward harmonics. IEEE Trans. Power Deliv. 2012, 27, 831-841. [CrossRef]

114. Sreekumar, P.; Khadkikar, V. Nonlinear load sharing in low voltage microgrid using negative virtual harmonic impedance. In Proceedings of the IECON 2015-41st Annual Conference of the IEEE Industrial Electronics Society, Yokohama, Japan, 9-12 November 2015; pp. 3353-3358.

115. Lorzadeh, I.; Abyaneh, H.A.; Savaghebi, M.; Guerrero, J.M. A hierarchical control scheme for reactive power and harmonic current sharing in islanded microgrids. In Proceedings of the 2015 17th European Conference on Power Electronics and Applications (EPE'15 ECCE-Europe), Geneva, Switzerland, 8-10 September 2015; pp. 1-10.

116. Moussa, H.; Shahin, A.; Martin, J.P.; Nahid-Mobarakeh, B.; Pierfederici, S.; Moubayed, N. Harmonic Power Sharing with Voltage Distortion Compensation of Droop Controlled Islanded Microgrids. IEEE Trans. Smart Grid 2018, 9, 5335-5347. [CrossRef]

117. Micallef, A.; Apap, M.; Spiteri-Staines, C.; Guerrero, J.M. Mitigation of Harmonics in Grid-Connected and Islanded Microgrids Via Virtual Admittances and Impedances. IEEE Trans. Smart Grid 2017, 8, 651-661. [CrossRef]

118. Guerrero, J.M.; Berbel, N.; Matas, J.; Sosa, J.L.; De Vicuña, L.G. Control of line-interactive UPS connected in parallel forming a microgrid. In Proceedings of the IEEE International Symposium on Industrial Electronics, Vigo, Spain, 4-7 June 2007; pp. 2667-2672.

119. Chen, Y.; Wang, Z.; Zhou, X.; Zhou, L.; Chen, Z.; Luo, A.; Wang, M. Seamless transfer control strategy for three-phase inverter in microgrid. In Proceedings of the 2016 IEEE 8th International Power Electronics and Motion Control Conference (IPEMC-ECCE Asia), Hefei, China, 22-26 May 2016; pp. 1759-1763.

120. Guerrerol, J.M.; Berbel, N.; Matas, J.; Sosa, J.L.; De Vicufia, L.G. Droop Control Method with Virtual Output Impedance for Parallel Operation of Uninterruptible Power Supply Systems in a Microgrid. In Proceedings of the APEC 07-Twenty-Second Annual IEEE Applied Power Electronics Conference and Exposition, Anaheim, CA, USA, 25 February-1 March 2007.

121. Guerrero, J.M.; Hang, L.; Uceda, J. Control of Distributed Uninterruptible Power Supply Systems. IEEE Trans. Ind. Electron. 2008, 55, 2845-2859. [CrossRef] 
122. Sangwongwanich, A.; Yang, Y.; Blaabjerg, F. A cost-effective power ramp-rate control strategy for single-phase two-stage grid-connected photovoltaic systems. In Proceedings of the 2016 IEEE Energy Conversion Congress and Exposition (ECCE), Milwaukee, WI, USA, 18-22 September 2016; pp. 1-7.

123. Salehi, V.; Radibratovic, B. Ramp rate control of photovoltaic power plant output using energy storage devices. In Proceedings of the 2014 IEEE PES General Meeting I Conference \& Exposition, National Harbor, MD, USA, 27-31 July 2014; pp. 1-5.

124. Kakimoto, N.; Satoh, H.; Takayama, S.; Nakamura, K. Ramp-rate control of photovoltaic generator with electric double-layer capacitor. IEEE Trans. Energy Convers. 2009, 24, 465-473. [CrossRef]

125. Van Haaren, R.; Morjaria, M.; Fthenakis, V. An energy storage algorithm for ramp rate control of utility scale PV (photovoltaics) plants. Energy 2015, 91, 894-902. [CrossRef]

126. Kasem, A.H.; El-Saadany, E.F.; El-Tamaly, H.H.; Wahab, M.A.A. Power ramp rate control and flicker mitigation for directly grid connected wind turbines. IET Renew. Power Gener. 2010, 4, 261. [CrossRef]

127. Cormode, D.; Cronin, A.D.; Richardson, W.; Lorenzo, A.T.; Brooks, A.E.; Dellagiustina, D.N. Comparing ramp rates from large and small PV systems, and selection of batteries for ramp rate control. In Proceedings of the 2013 IEEE 39th Photovoltaic Specialists Conference (PVSC), Tampa, FL, USA, 16-21 June 2013; pp. 1805-1810.

128. De la Parra, I.; Marcos, J.; García, M.; Marroyo, L. Control strategies to use the minimum energy storage requirement for PV power ramp-rate control. Sol. Energy 2015, 111, 332-343. [CrossRef]

129. Marcos, J.; Storkël, O.; Marroyo, L.; Garcia, M.; Lorenzo, E. Storage requirements for PV power ramp-rate control. Sol. Energy 2014, 99, 28-35. [CrossRef]

(C) 2019 by the authors. Licensee MDPI, Basel, Switzerland. This article is an open access article distributed under the terms and conditions of the Creative Commons Attribution (CC BY) license (http://creativecommons.org/licenses/by/4.0/). 